\title{
A Dynamic Investigation of the Impact Failure Analysis of the Friction Plate in a Planetary Transmission System
}

\author{
Shenlong Li \\ China North Vehicle Research Institute, Beijing, 100081, P. R. China. \\ Shuhan Zhou \\ College of Mechanical Engineering, Chongqing University, Chongqing, 400044, P.R. China.
}

\begin{abstract}
(Received 22 May 2020; accepted 29 August 2020)
A clear understanding of both vibrations and the impact forces of planetary transmission systems is very helpful for decreasing impact failures of their friction discs and preventing serious accidents of the system. This study presents a multibody dynamic (MBD) investigation based on a commercial MBD software to predict the vibrations and impact forces of the friction disc in a planetary transmission system. In the MBD model, the radial clearance of the planet bearing is formulated, as well as the backlash between the outer gear teeth of the ring and friction disc teeth. However, the previous works in the literature only considered single radial clearance or backlash. The influences of the radial clearance of the planet bearing and backlash between the outer gear teeth of the ring and friction disc teeth on the vibrations and impact forces of the friction disc in the planetary transmission system are studied. The results give that a smaller radial clearance and backlash can be useful for decreasing both the vibrations and impact forces of the friction disc in the planetary transmission system. The MBD method can be applied to predict the vibrations and impact forces in the planetary transmission system as well.
\end{abstract}

\section{INTRODUCTION}

Planetary transmission systems are one of the key components in many industry applications such as heavy trucks, ships, high-speed trains etc. ${ }^{1}$ As the main braking components of the planetary transmission systems, friction discs are their most key components. Due to their complicated working conditions, impact failures, such as plastic deformations and cracks, are usually generated in the friction discs. A sample of the crack failure of a frictional plate is shown by Wang. ${ }^{2}$ Thus, a clear understanding of the impact failures of the friction discs is very helpful for preventing serious accidents of the planetary transmission systems.

Many studies have reported to analyze the impact failures of different friction discs. Some works were focused on analyzing fracture failures of the friction discs by using chemical analysis methods. ${ }^{3-6}$ Moreover, dynamic analysis methods are one of the most useful methods for the impact failures of the friction discs in the planetary transmission systems. Majcherczak and Dufrénoy ${ }^{7}$ presented a multibody dynamic (MBD) model and a finite element (FE) model for a braking system to discuss the dynamics of the system with external and internal loadings. Kang et al. ${ }^{8}$ used a FE model and an analytical model to predict the vibration instability caused by the transverse doublet modes of a thin annular plate. Zeng and Luo $^{9}$ developed an analytical model of a disc brake in a railway vehicle system to analyze nonlinear friction vibrations between the disc and brake lining. Olshevskiy et al. ${ }^{10}$ established a FE model to discuss the effects of the thermomechanical factors on the contact pressure distribution, temperature, and wear patterns of a brake system. Sfarni et al. ${ }^{11}$ established a FE model for a clutch disc to analyze the cushion curve. $\mathrm{Li}$ et al. ${ }^{12,13}$ developed a MBD model to predict the vibrations and impact forces of a friction disc system. Olshevskiy et al. ${ }^{14}$ proposed a MBD model and a FE model to study the tribological characteristics of a friction pair with a centre bowl and a centre plate. Wei et al. ${ }^{15}$ introduced a dynamic model for a brake system combined with the tangential motion of the pad and torsional motion of the disk to discuss the noise and vibration of the brake system.

The above studies show that the failures of the friction discs have been studied by using chemical analysis methods, the FE method, the MBD method, and the analytical method. However, the effects of the excitations of the supported planetary gear system were ignored in most works. Although the supported planetary gear system was considered in Refs., ${ }^{12,13}$ the planetary gear system and inner hub of the friction disc were fixed as one rigid bodies, and the gears and bearings in the planetary gear system were ignored in their MBD model. Therefore, the above models cannot accurately consider the effects of the clearances of the planet bearings and interactions between the mating components in the supported planetary gear system on the vibrations and impact forces of their friction discs. This study is conducted to overcome this gap.

On the other hand, numerous works have been reported to study the vibrations of planetary gear systems. Kahraman et al. ${ }^{16}$ developed a dynamic FE model for a planetary gear system to analyze the effect of the gear flexibility on the dynamic system behaviors. Ambarisha and Parker ${ }^{17}$ proposed a lumped-parameter model and a FE model for a planetary gear system to describe the nonlinear system vibrations. Lethé et al. ${ }^{18}$ established a MBD model to predict the vibrations, durability characteristics and noise emissions of a planetary gearbox. Halsen et al. ${ }^{19}$ developed a torsional MBD model for a wind turbine planetary gearbox to discuss its modal behavior. Xing and Moan ${ }^{20}$ presented a MBD simulation method that combined the FE and MBD models to predict the vibrations of a planetary gearbox used in a wind turbine. Helsen et al. ${ }^{21}$ developed a flexible MBD model of a planetary gearbox in a wind turbine to analyze the mode shapes of the system. 
Jin et al. ${ }^{22}$ established a flexible MBD model for a planetary transmission system in a wind turbine to predict the vibrations of the system. Li et al. ${ }^{23}$ proposed an aero-servo-elastic simulation method combined with the MBD and computational fluid dynamic methods for a planetary transmission system in a wind turbine to analyze the interactions between the elastic blades, turbulent wind, drivetrain dynamics, and rotor aerodynamics. Ma et al., ${ }^{24-26}$ presented the MBD and FE models to study the vibrations of the cracked gear systems. Although the above works introduced various MBD, FE, and analytical methods to study the vibrations of the planetary transmission system, the effects of the excitations in the planetary gear system on the friction disc were not discussed in their works. Yu et al. ${ }^{27,28}$ introduced an analytical dynamic model to formulate the effects of the spatial cracks on the vibrations of gear systems. Liang et al., ${ }^{29}$ Xin, ${ }^{30}$ and Liang et al. ${ }^{31}$ studied the dynamic vibrations of the planetary gear system with backlash and the cracks. Xue et al. ${ }^{32}$ studied the angular amplitude modulation caused by the planet bearings. However, in practice, the clearance and manufacturing errors in the bearings have a significant effect on the system vibrations. ${ }^{33-36}$ Thus, the clearance of the planet bearing should be considered in the vibration analysis of the planetary transmission systems. Guo and Parker ${ }^{37,38}$ proposed a series of works to study the influences of the bearing clearance and the internal backlash on the vibrations of the planetary gear systems. Raghuwanshi and Parey ${ }^{39}$ used the FE method to study the influence of backlash on the mesh stiffness of a spur gear system. Moshrefzadeh and Fasana ${ }^{40}$ presented a MBD model considering the bearing clearance and internal backlash of a planetary gear system. Liu et al. ${ }^{41}$ studied the bearing clearance and backlash on the vibrations of a spur gear system. Zhang et al. ${ }^{42}$ studied the gear backlash on the transmission error and load distribution of a hoist two-stage planetary gear system.

Moreover, Chaari et al. ${ }^{1}$ proposed a dynamic model of a planetary gear with tooth pitting and cracking. The support bearings in the planetary gear were not considered in their model. Wang ${ }^{2}$ only studied the impact forces between the ring gear and friction disc, which used a rigid fixed ring gear in this model. However, for a planetary gear system, the bearing clearance, bearing deformation, and floated ring will greatly affect the impact forces between the ring gear and friction disc. The above parameters will be completely considered in this work. Thus, this work is not a simple combination of those in Refs. 1,2

To overcome the above problems, this study presents a MBD investigation based on a commercial MBD software to predict the vibrations and impact forces of the friction disc in a planetary transmission system. Both the radial clearance of the planet bearing and backlash between the outer gear teeth of the ring and friction disc teeth are formulated in the MBD model, which were not considered by the previous works in the literature. According the practical working conditions, since the main reason for failure with the crack type of friction disc in this work is caused by the unexpected impact forces between the ring gear and friction disc, which is very different from those given by Mackin et al. ${ }^{3}$ Thus, this work is focused on the vibrations and impact forces. Here, the influences of the radial clearance of the planet bearing and backlash between the outer gear teeth of the ring and friction disc teeth on the vibrations and impact forces of the friction disc in the planetary transmission system are studied. The results give that a smaller radial clearance and backlash can be useful for decreasing the vibrations and impact forces of the friction disc in the plane- tary transmission system. It also seems the MBD method can be applied to predict the vibrations and impact forces in the planetary transmission system.

\section{A BRIEF FORMULATION FOR THE MBD METHOD}

\subsection{Contact Force Calculation Algorithm}

An impact function method based on Hertzian contact theory was used to formulate the contact forces between the mating bodies in the planetary gear system. In this method, the contact force was given by: ${ }^{43}$

$$
\begin{aligned}
& F= \\
& \begin{cases}K\left(s_{0}-s\right)^{e}-C\left(\frac{\mathrm{d} s}{\mathrm{~d} t}\right) \operatorname{STEP}\left(s, s_{0}-d, 1, s_{0}, 0\right) s \geq s_{0} \\
0 & s<s_{0}\end{cases}
\end{aligned}
$$

where $K$ was the contact stiffness between the mating bodies, $s_{0}$ was the reference distance between the mating bodies, $s$ was the real distance between the mating bodies, $e$ was the force exponent, $C$ was the damping coefficient, $t$ was the time, STEP was a step function, and $d$ was the penetration depth. $K$ was calculated by:

$$
K=\frac{4}{3}\left(\frac{R_{1} R_{2}}{R_{1}+R_{2}}\right)^{0.5}\left(\frac{1-v_{1}^{2}}{E_{1}}+\frac{1-v_{2}^{2}}{E_{2}}\right)^{-1}
$$

where $R_{1}$ and $R_{2}$ were the radii of the mating bodies, $E_{1}$ and $E_{2}$ were the elastic modulus of the mating bodies, and $v_{1}$ and $v_{2}$ were the Poisson ratios of the mating bodies. Moreover, $C$ was defined by:

$$
C=2 \xi \sqrt{K m^{*}}
$$

where $\xi$ was the damping ratio, and $m^{*}$ is the equivalent mass. The contact stiffness of the planet bearing was calculated by:

$$
\delta=3.84 \times 10^{-5} \frac{Q^{0.9}}{l^{0.8}}
$$

where $Q$ was the contact force and $l$ was the contact length.

\subsection{Dynamic Simulation Method}

The equations of the motion for the planetary transmission system used in the simulation software was written as: ${ }^{43}$

$$
\frac{\mathrm{d}}{\mathrm{d} t}\left(\frac{\partial T}{\partial \dot{s}_{j}}\right)-\frac{\partial T}{\partial s_{j}}=Q_{j}+\sum_{i=1}^{n} \lambda_{i} \frac{\partial \Phi}{\partial s_{j}}
$$

where $T$ was the kinetic energy of the components of the planetary transmission system, $s_{j}$ was the generalized coordinates of the components of the planetary transmission system, $Q_{j}$ was the generalized force at $s_{j}, n$ was the number of the constraint, $\lambda$ was Lagrange multiplier, and $\Phi$ was the constraint function. In Eq. (4), the last term describes the constraint forces of the components of the planetary transmission system. $s$ is given by:

$$
s=[x, y, z, \psi, \theta, \varphi]^{T}
$$

where $x, y$, and $z$ were the Cartesian coordinates of the rigid bodies of the planetary transmission system, and $\psi, \theta$, and $\varphi$ were the Eulerian angles of the rigid bodies of the planetary 


\begin{tabular}{|c|c|c|c|c|}
\hline Parameters & $\begin{array}{c}\text { Planet } \\
\text { gear }\end{array}$ & $\begin{array}{l}\text { Sun } \\
\text { gear }\end{array}$ & $\begin{array}{l}\text { Ring } \\
\text { gear }\end{array}$ & $\begin{array}{c}\begin{array}{c}\text { Friction } \\
\text { disc }\end{array}\end{array}$ \\
\hline Normal module $(\mathrm{mm})$ & \multicolumn{4}{|c|}{4} \\
\hline Number of teeth & 15 & 30 & 60 & 75 \\
\hline Number & 3 & \multicolumn{3}{|c|}{1} \\
\hline Normal pressure angle $\left({ }^{\circ}\right)$ & \multicolumn{4}{|c|}{20} \\
\hline Face width $(\mathrm{mm})$ & & 25 & & 4 \\
\hline
\end{tabular}

transmission system. The Cartesian coordinates are marked in Fig. 1. In this work, according to the practical working conditions, the vibrations in the $z$ direction can be ignored due to the mounting conditions. Thus, this model only considered the vibrations in the $x$ and $y$ directions.

In the MBD model, the Eq. (1) was used to calculate the contact forces between the contacting bodies; the Eq. (2) was used to calculate the contact stiffness between the meshing gears; the Eq. (3) was used to calculate the damping value between the meshing gears; the Eq. (4) was used to calculate the contact stiffness between the roller and raceway of the planet bearing; moreover, the Eq. (5) was the calculation algorithm used in the software for calculating the kinetic energy and dynamic behaviors of the rigid bodies in the MBD model.

\section{RESULTS AND DISCUSSIONS}

In this study, the vibrations and impact forces of a planetary transmission system with one friction disc is analyzed by using a MBD method. The dynamic model is established in a commercial ADAMS software. As plotted in Fig. 1, the studied planetary transmission system includes one sun gear, three planet gear, three planet bearings, one carrier, one ring gear, and one friction disc. In the MBD model, the sun gear is fixed on the ground according the practical mounting conditions. Geometrics of the planetary transmission system are given in Tables 1 and 2. The backlash between the outer gear teeth of the ring and friction disc teeth is formulated as shown in Fig. 1, as well as the radial clearance of the planet bearing. A grease lubrication condition is considered in the planet bearing, whose calculation algorithm is listed in MSC Adams manual. ${ }^{43}$ A clockwise rotational speed of the carrier $\left(n_{c}\right)$ is assumed to be $300 \mathrm{r} / \mathrm{min}, 600 \mathrm{r} / \mathrm{min}$, and $1200 \mathrm{r} / \mathrm{min}$, respectively. The normal backlash between the outer gear teeth of the ring and friction disc teeth $\left(d_{t}\right)$ is assumed to be $0.01 \mathrm{~mm}$, $0.1 \mathrm{~mm}, 0.2 \mathrm{~mm}, 0.3 \mathrm{~mm}, 0.4 \mathrm{~mm}, 0.6 \mathrm{~mm}, 0.8 \mathrm{~mm}$, and $1.0 \mathrm{~mm}$, respectively. The normal backlash between the outer gear teeth of the ring gear and friction disc teeth is obtained by the measurement results in the practical conditions. The radial clearance of the planet bearing is assumed to be $0.0125 \mathrm{~mm}$, $0.0225 \mathrm{~mm}, 0.0325 \mathrm{~mm}, 0.0400 \mathrm{~mm}$, and $0.0475 \mathrm{~mm}$, respectively. In this work, the vibration of the friction disc and the impact forces between the ring gear and friction disc will be studied in the next sections.

Figure 1(b) shows the proposed MBD model in the software. In this model, the sun gear is fixed with the ground; a revolution joint is used to fix the carrier and support shaft. The input speed is applied on the carrier; the roller bearing model from the ADAMS software used for model the roller bearings; the contact model is used to formulate the meshing relationship between the gears; the moment is applied on the friction disc. Based the suggested value in the software, the damping value used for the bodies is $10 \mathrm{~N} /(\mathrm{m} / \mathrm{s})$. In this model, the axial vibration of the friction disc is not considered according to the practical working conditions.
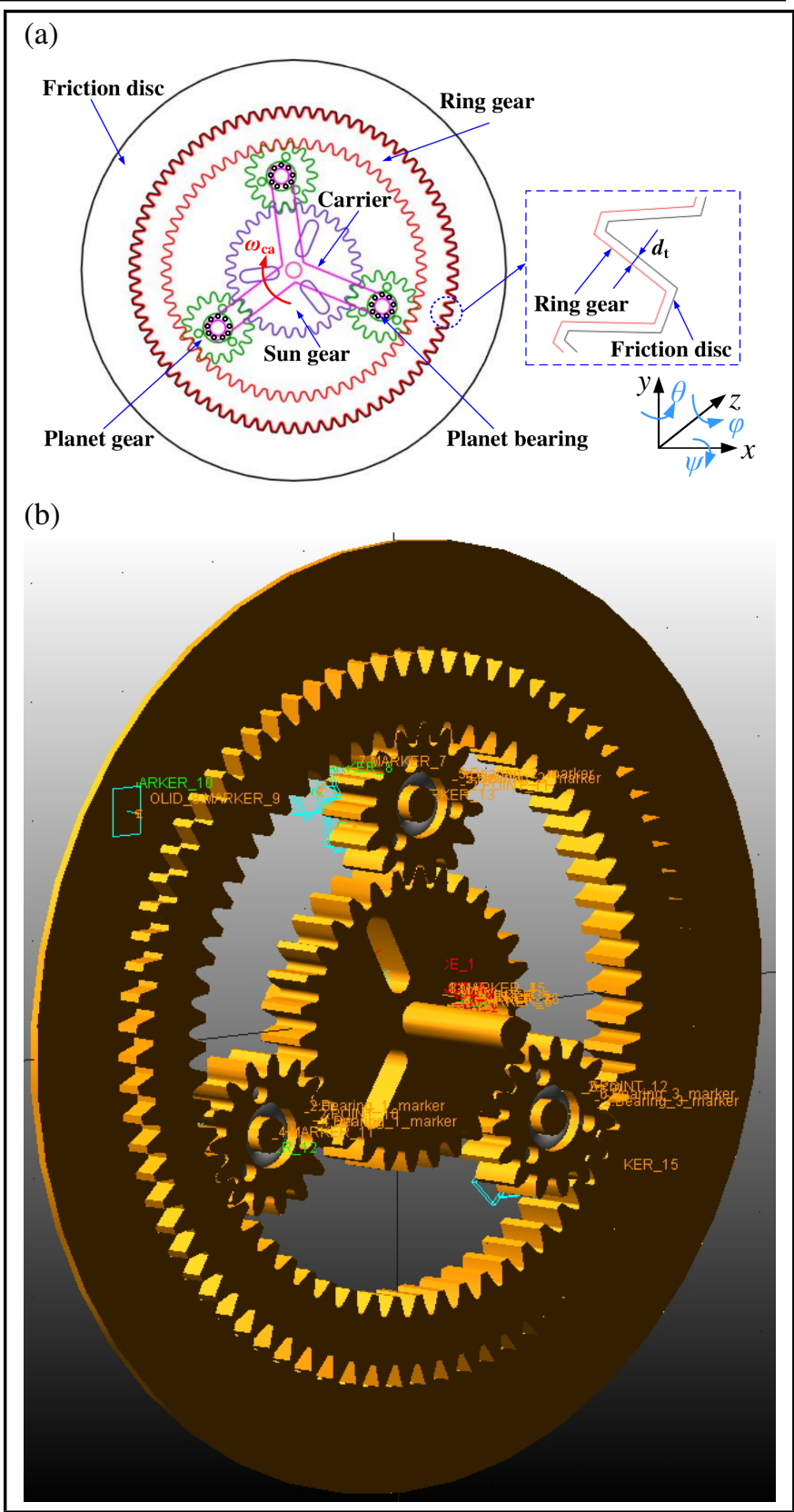

Figure 1. (a) Schematic of a planetary transmission system and (b) MBD model.

Table 2. Geometrics for the studied planet bearing NA4902.

\begin{tabular}{|l|l|}
\hline Parameters & Value \\
\hline Bore diameter $(\mathrm{mm})$ & 21.5 \\
\hline Roller diameter $(\mathrm{mm})$ & 2.07 \\
\hline Roller length $(\mathrm{mm})$ & 19.10 \\
\hline Number of rollers & 8 \\
\hline Number of rows & 1 \\
\hline
\end{tabular}

\subsection{Influence of the Radial Clearance of the Planet Bearing on the Vibrations of the Friction Disc}

Figures 2 to 4 plot the influence of the radial clearance of the planet bearing on the displacements of the friction disc under different carrier speeds. Since the statistics of the time-domain vibrations can be useful for analyzing the dynamic characteristics of rotating system, ${ }^{44,45}$ this following section will discuss the statistics. In Fig. 3, the normal backlash $\left(d_{t}\right)$ is assumed to be $0.01 \mathrm{~mm}$. In Fig. 4 , the carrier speed $\left(n_{c}\right)$ is assumed 


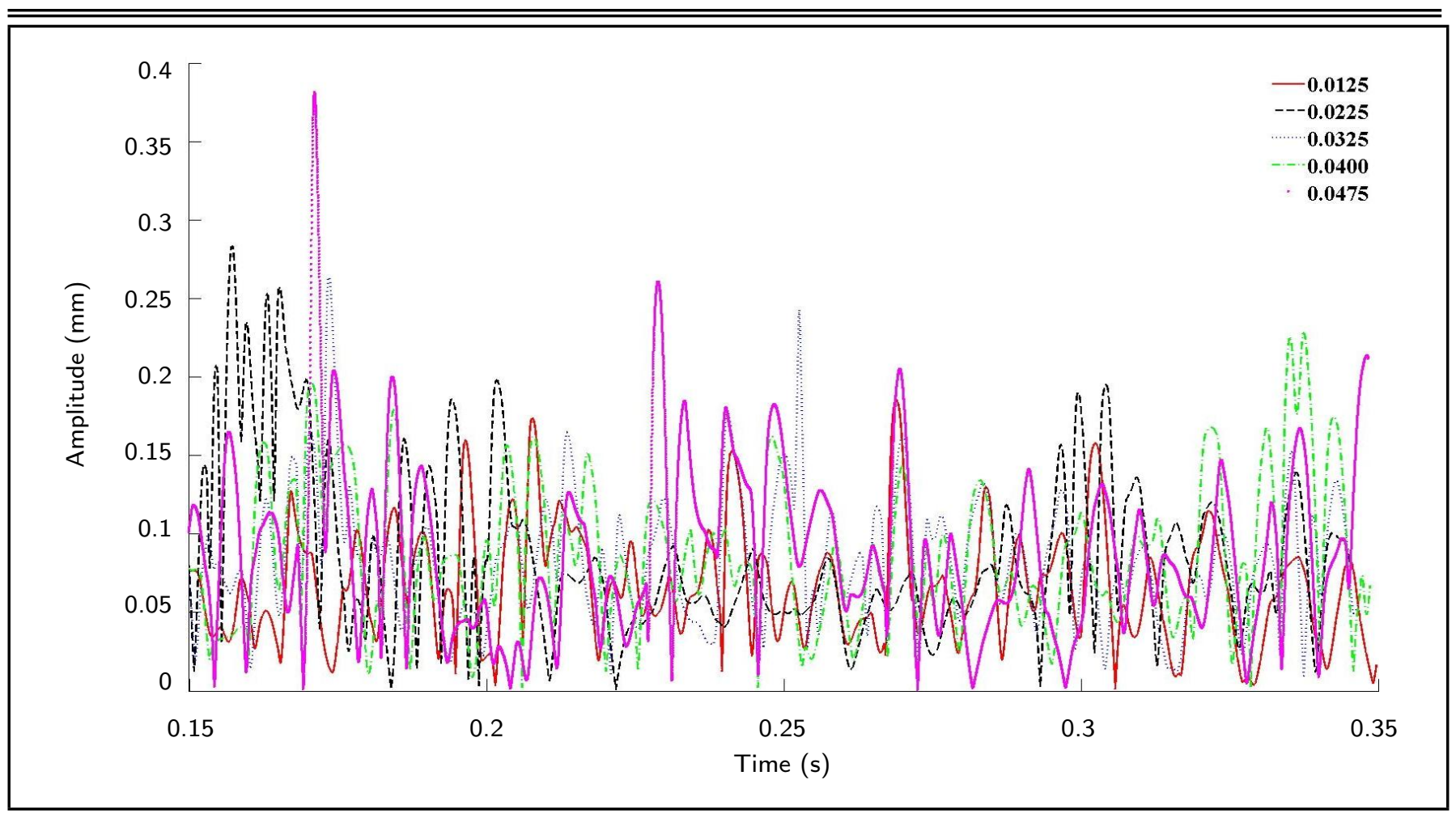

Figure 2. Influence of the radial clearance of the planet bearing on the time-domain displacements of the friction disc.

to be $1200 \mathrm{r} / \mathrm{min}$ and the normal backlash $\left(d_{t}\right)$ is assumed to be $0.1 \mathrm{~mm}, 0.2 \mathrm{~mm}$, and $0.3 \mathrm{~mm}$, respectively. The root mean square (RMS) value, peak value (PV), and peak to peak (PTP) value of the displacement of the friction disc are used to demonstrate the influence of the radial clearance of the planet bearing on the vibrations of the friction disc. The details of the calculation methods for the above statistics were listed in Refs. ${ }^{46}$ As plotted in Fig. 3, for the system with a small normal backlash $\left(d_{t}=0.01 \mathrm{~mm}\right)$, the vibration level of the friction disc almost increases with the radial clearance of the planet bearing and the carrier speed. It seems that the friction disc has a smaller vibration level when the radial clearance of the planet bearing is chosen to be from $0.0125 \mathrm{~mm}$ to $0.0225 \mathrm{~mm}$. As depicted in Fig. 4, for the system with a large normal backlash under a higher carrier speed, the vibration level of the friction disc also almost increases with the radial clearance of the planet bearing and the carrier speed too; when $d_{t}$ is $0.2 \mathrm{~mm}$ and $0.3 \mathrm{~mm}$, a smaller vibration level is observed when the radial clearance of the planet bearing is chosen to be from $0.0225 \mathrm{~mm}$ to $0.0325 \mathrm{~mm}$; when $d_{t}$ is $0.4 \mathrm{~mm}$, a smaller vibration level is observed when the radial clearance of the planet bearing is chosen to be from $0.0125 \mathrm{~mm}$ to $0.0225 \mathrm{~mm}$.

Figure 5 gives the influence of the radial clearance of the planet bearing on the angular speed of the friction disc under different carrier speeds. Here, only PV and PTP values of the angular speed of the friction disc are compared since the RMS value has a slight difference between the studies cases. As given in Fig. 5, the angular speed fluctuation of the friction disc almost increases with the radial clearance of the planet bearing and carrier speed. When $n_{c}=300 \mathrm{r} / \mathrm{min}$ and $1200 \mathrm{r} / \mathrm{min}$, the minimum PV and PTP values can be observed for the case with a radial clearance of $0.0125 \mathrm{~mm}$. When $n_{c}=600 \mathrm{r} / \mathrm{min}$, the minimum PV and PTP values can be observed for the case with a radial clearance of $0.0225 \mathrm{~mm}$. Moreover, the angular speed fluctuation of the friction disc for the case with the normal backlash of $0.2 \mathrm{~mm}$ is smaller than those for the other two studied backlash cases. The above results give that the radial clearance of the planet bearing has a great influence on the vibrations of the friction disc. The results from Figs. 2 to 4 show that the vibration level of the friction disc can be reduced by changing the radial clearance of the planet bearing and backlash the outer gear teeth of the ring and friction disc teeth. Furthermore, a smaller radial clearance of the planet bearing can be useful for reducing the vibration level of the friction disc.

\subsection{Influence of the Backlash on the Vibrations of the Friction Disc}

Figure 6 depicts the influence of the backlash between the outer gear teeth of the ring and friction disc teeth $\left(d_{t}\right)$ on the displacements of the friction disc under different carrier speeds. Here, the radial clearance of the planet bearing is assumed to be $0.0125 \mathrm{~mm}$. As depicted in Fig. 6, the vibration level of the friction disc almost increase with the backlash and carrier speed. The case with a normal backlash of $0.2 \mathrm{~mm}$ produces a smaller vibration level in the studied backlash cases.

Figure 7 illustrates the influence of the backlash on the angular speed fluctuation of the friction disc under different carrier speeds. Here, the radial clearance of the planet bearing is also assumed to be $0.0125 \mathrm{~mm}$. As given in Fig. 7, the angular speed fluctuation of the friction disc also almost increases with the backlash and carrier speed. Furthermore, the case with a normal backlash of $0.2 \mathrm{~mm}$ produces a smaller angular speed fluctuation in the studied backlash cases. Figure 8 shows the influence of the radial clearance of the planet bearing on the angular speed fluctuation of the friction disc under different backlash cases. In Fig. 8, the carrier speed $\left(n_{c}\right)$ is assumed to be $1200 \mathrm{r} / \mathrm{min}$. As shown in Fig. 8, the angular speed fluctuation of the friction disc also almost increases with the backlash and radial clearance of the planet bearing. The above results show that the radial clearance of the planet bearing has a great influence on the angular vibrations of the friction disc. The results from Figs. 7 to 8 show that the angular vibration level of 


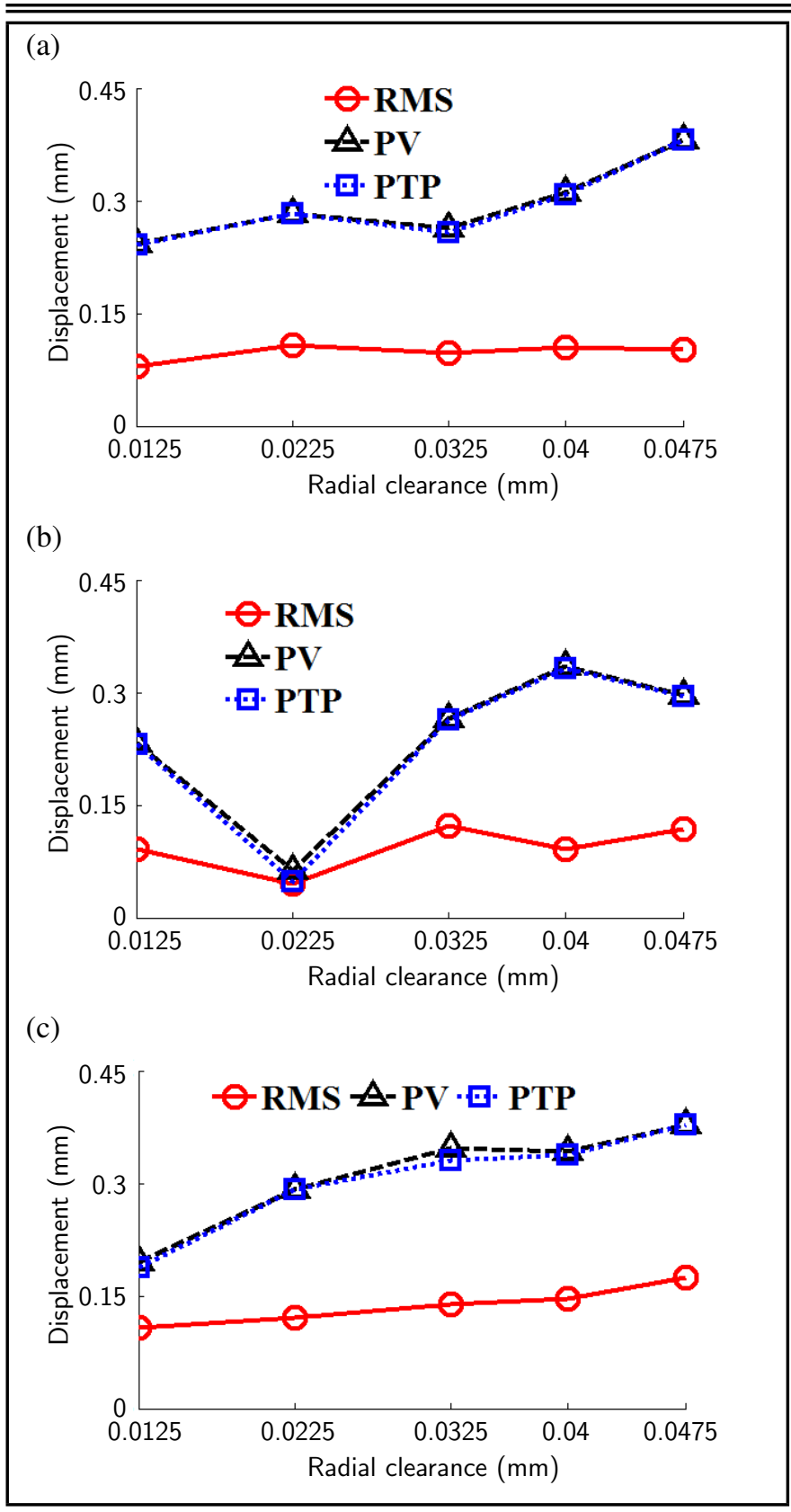

Figure 3. Influence of the radial clearance of the planet bearing on the displacements of the friction disc with $d_{t}=0.01 \mathrm{~mm}$. (a) $n_{c}=300 \mathrm{r} / \mathrm{min}$, (b) $n_{c}=600 \mathrm{r} / \mathrm{min}$, and (c) $n_{c}=1200 \mathrm{r} / \mathrm{min}$.

the friction disc can be reduced by changing the radial clearance of the planet bearing and backlash the outer gear teeth of the ring and friction disc teeth. In addition, a smaller radial clearance can be useful to reduce the angular vibration level of the friction disc.

\subsection{Influence of the Radial Clearance of the Planet Bearing on the Impact Force of the Friction Disc}

Figure 9 illustrates the influence of the radial clearance of the planet bearing on the impact force of the friction disc under different carrier speed. Here, the normal backlash is assumed to be $0.01 \mathrm{~mm}$. As shown in Fig. 9, the impact forces of the friction disc almost increase with the radial clearance of the planet bearing and carrier speed. It seems that the friction disc has a smaller impact force when the radial clearance of the planet bearing is chosen to be from $0.0125 \mathrm{~mm}$ to $0.0225 \mathrm{~mm}$.

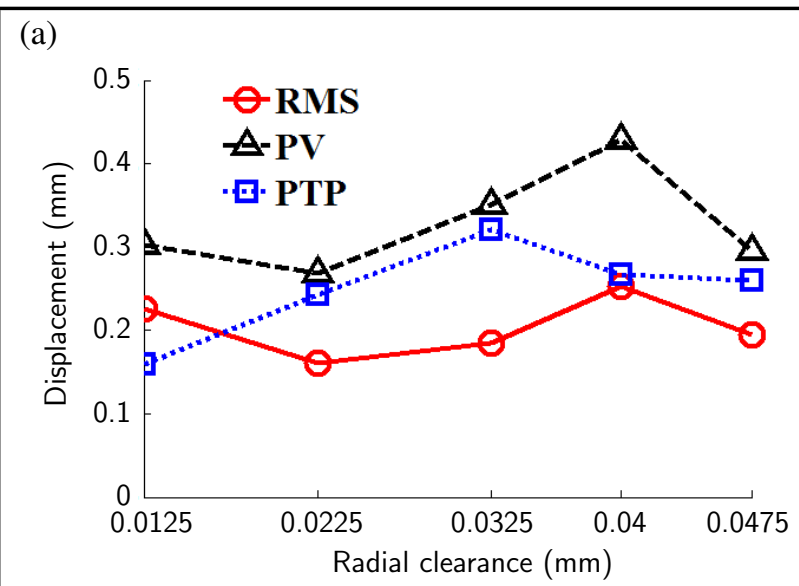

(b)

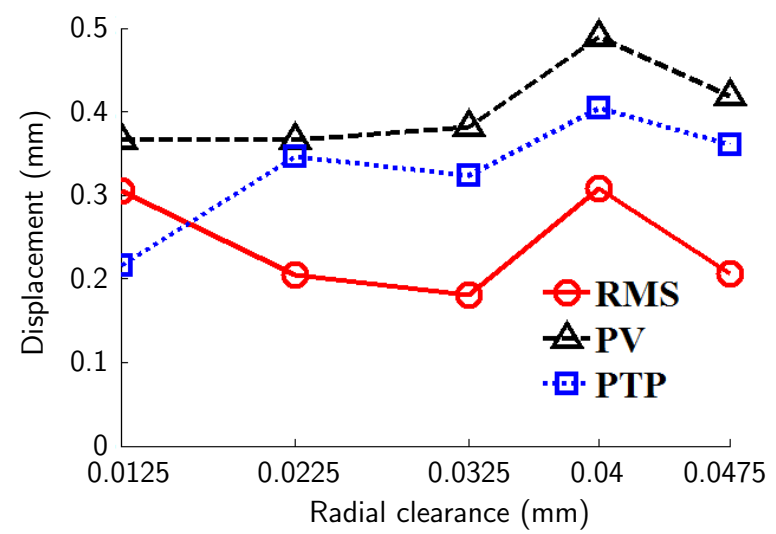

(c)

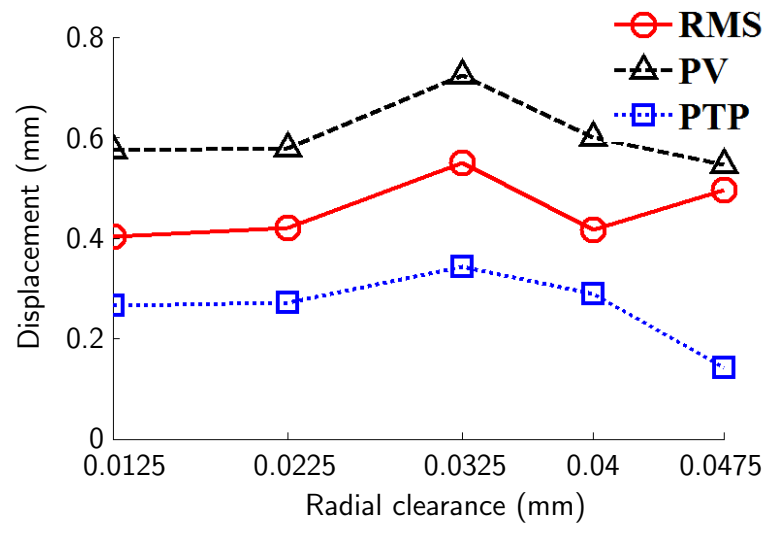

Figure 4. Influence of the radial clearance of the planet bearing on the displacements of the friction disc with $n_{c}=1200 \mathrm{r} / \mathrm{min}$. (a) $d_{t}=0.2 \mathrm{~mm}$, (b) $d_{t}=0.3 \mathrm{~mm}$, and (c) $d_{t}=0.4 \mathrm{~mm}$.

This results are similar as those in Section 3.1. The above results show that the radial clearance of the planet bearing and carrier speed have a great influence on the impact force of the friction disc. The results from Fig. 9 show that the impact force of the friction disc can be reduced by changing the radial clearance of the planet bearing and backlash the outer gear teeth of the ring and friction disc teeth. Moreover, a smaller radial clearance can be useful to reduce the impact force of the friction disc.

\subsection{Influence of the Backlash on the Impact Force of the Friction Disc}

Figure 10 plots the influence of the backlash on the impact force of the friction disc under different carrier speed. Here, 


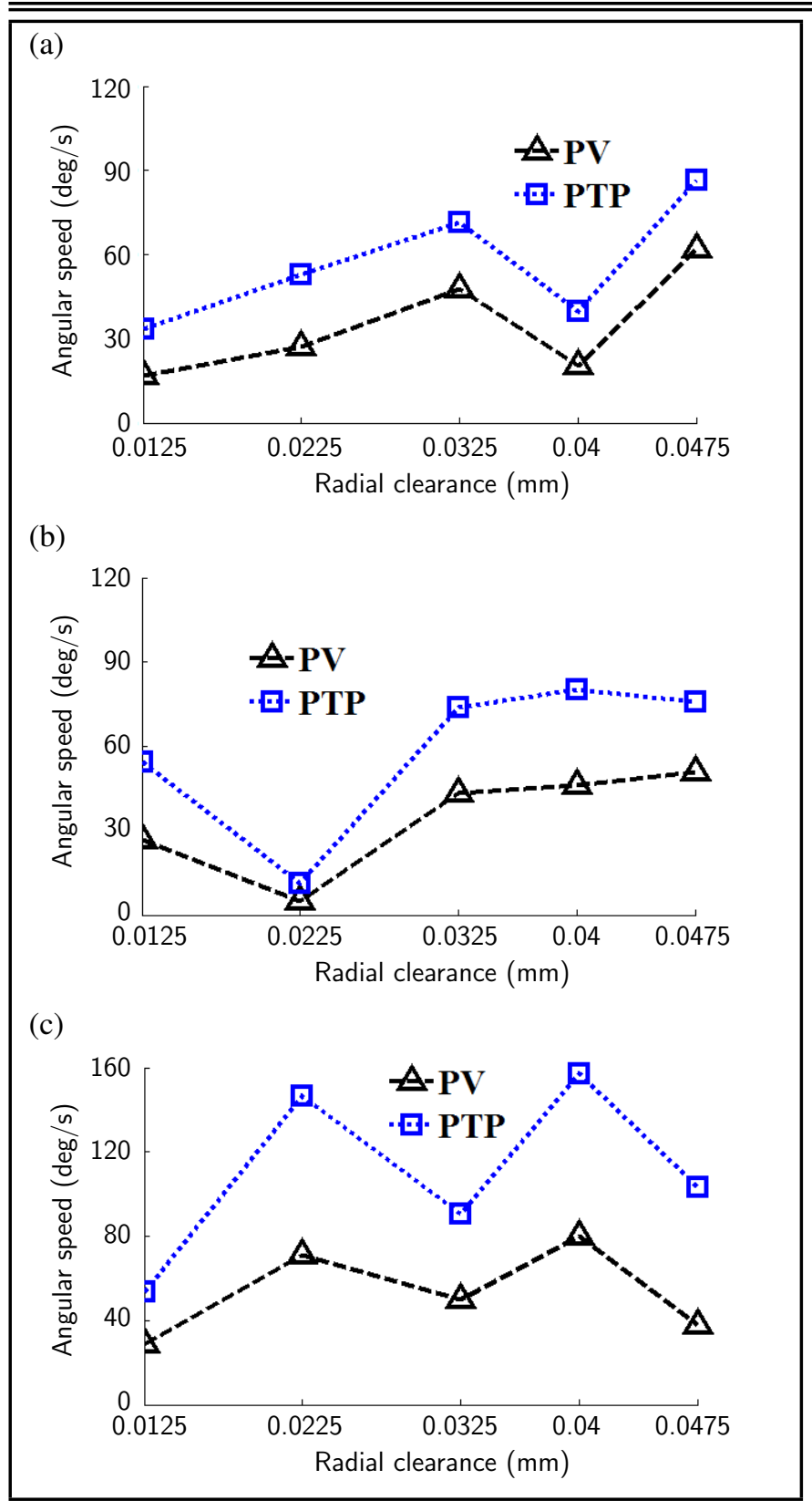

Figure 5. Influence of the radial clearance of the planet bearing on the angular speed of the friction disc with $d_{t}=0.01 \mathrm{~mm}$. (a) $n_{c}=300 \mathrm{r} / \mathrm{min}$, (b) $n_{c}=600 \mathrm{r} / \mathrm{min}$, and (c) $n_{c}=1200 \mathrm{r} / \mathrm{min}$.

the radial clearance of the planet bearing is assumed to be $0.0125 \mathrm{~mm}$. As given in Fig. 10, the impact forces of the friction disc almost increase with the backlash and carrier speed. It seems that the friction disc has a smaller impact force when the radial clearance of the planet bearing is chosen to be from $0.0125 \mathrm{~mm}$ to $0.0225 \mathrm{~mm}$. This results are similar as those in Section 3.2. Figure 11 shows the influence of the radial clearance of the planet bearing on the impact force of the friction disc under different backlash cases. In Fig. 11, the carrier speed $\left(n_{c}\right)$ is assumed to be $1200 \mathrm{r} / \mathrm{min}$. As shown in Fig. 11, the impact forces of the friction disc almost increase with the backlash; for $d_{t}=0.2 \mathrm{~mm}$, the friction disc has smaller impact force when the radial clearance of the planet bearing is chosen to be from $0.0125 \mathrm{~mm}$ to $0.0225 \mathrm{~mm}$; for $d_{t}=0.3 \mathrm{~mm}$ and $0.4 \mathrm{~mm}$, the friction disc has smaller impact force when the radial clearance of the planet bearing is chosen to be $0.0125 \mathrm{~mm}$. The above results show that the normal backlash have a great influence on the impact force of the friction disc. The results from Figs. 10 and 11 show that the impact force of the fric-

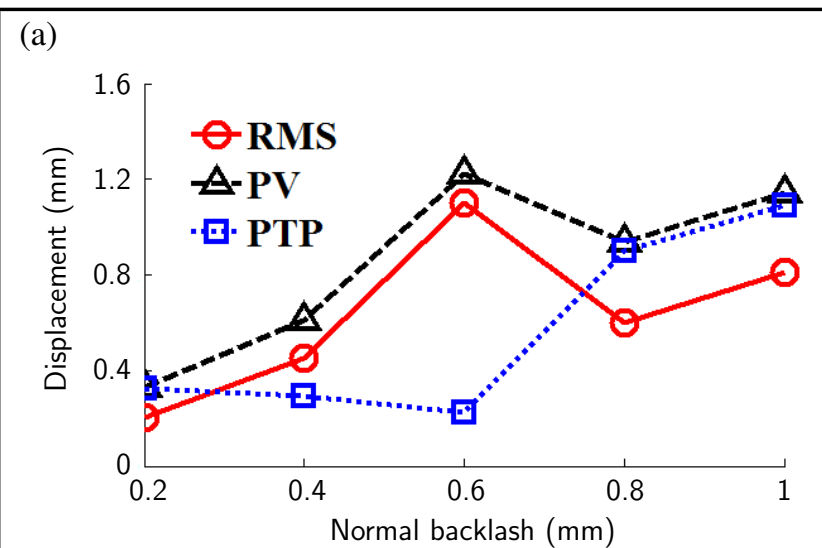

(b)

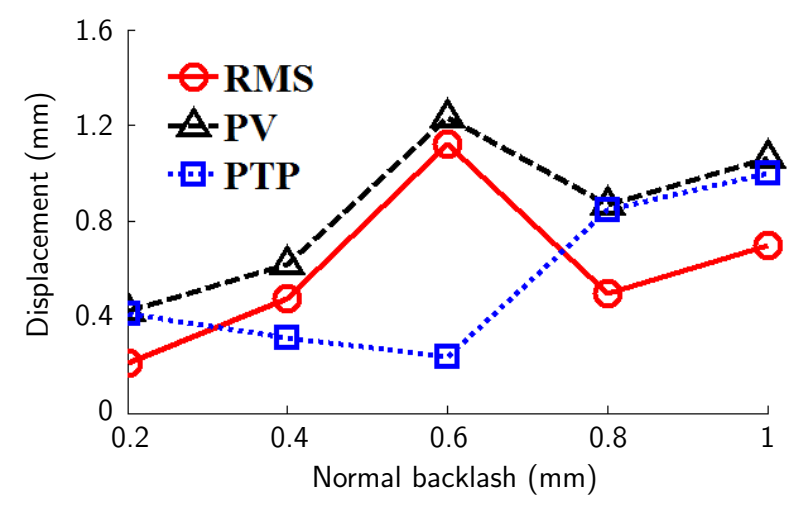

(c)

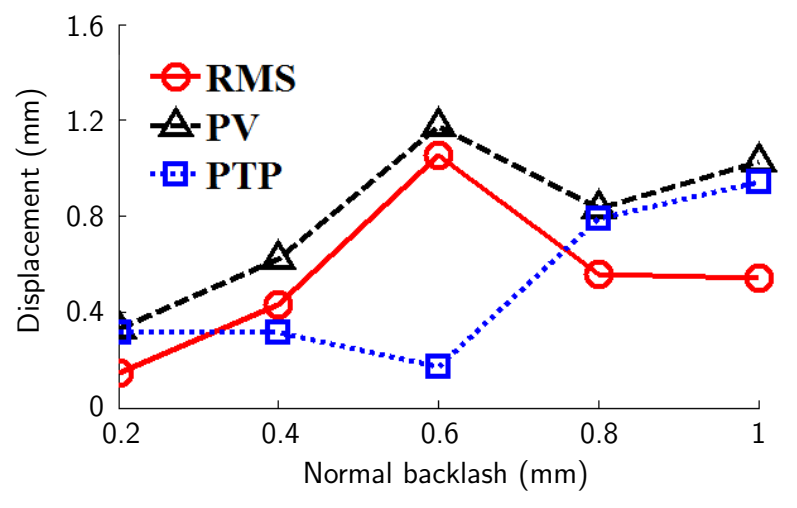

Figure 6. Influence of the backlash on the displacements of the friction disc with $\eta_{p}=0.0125 \mathrm{~mm}$. (a) $n_{c}=300 \mathrm{r} / \mathrm{min}$, (b) $n_{c}=600 \mathrm{r} / \mathrm{min}$, and (c) $n_{c}=1200 \mathrm{r} / \mathrm{min}$.

tion disc can be reduced by changing the radial clearance of the planet bearing and backlash the outer gear teeth of the ring and friction disc teeth. Furthermore, a smaller radial clearance can be useful to reduce the impact force of the friction disc.

\section{CONCLUSIONS}

This study presents a MBD investigation based on a commercial MBD software to predict the vibrations and impact forces of the friction disc in a planetary transmission system. Both the radial clearance of the planet bearing and backlash between the outer gear teeth of the ring and friction disc teeth are formulated in the MBD model, which were not considered by the previous works in the literature. The influences of the radial clearance of the planet bearing and backlash between the outer gear teeth of the ring and friction disc teeth on the vibrations and impact forces of the friction disc in the planetary transmission system are studied. The results show that a smaller 


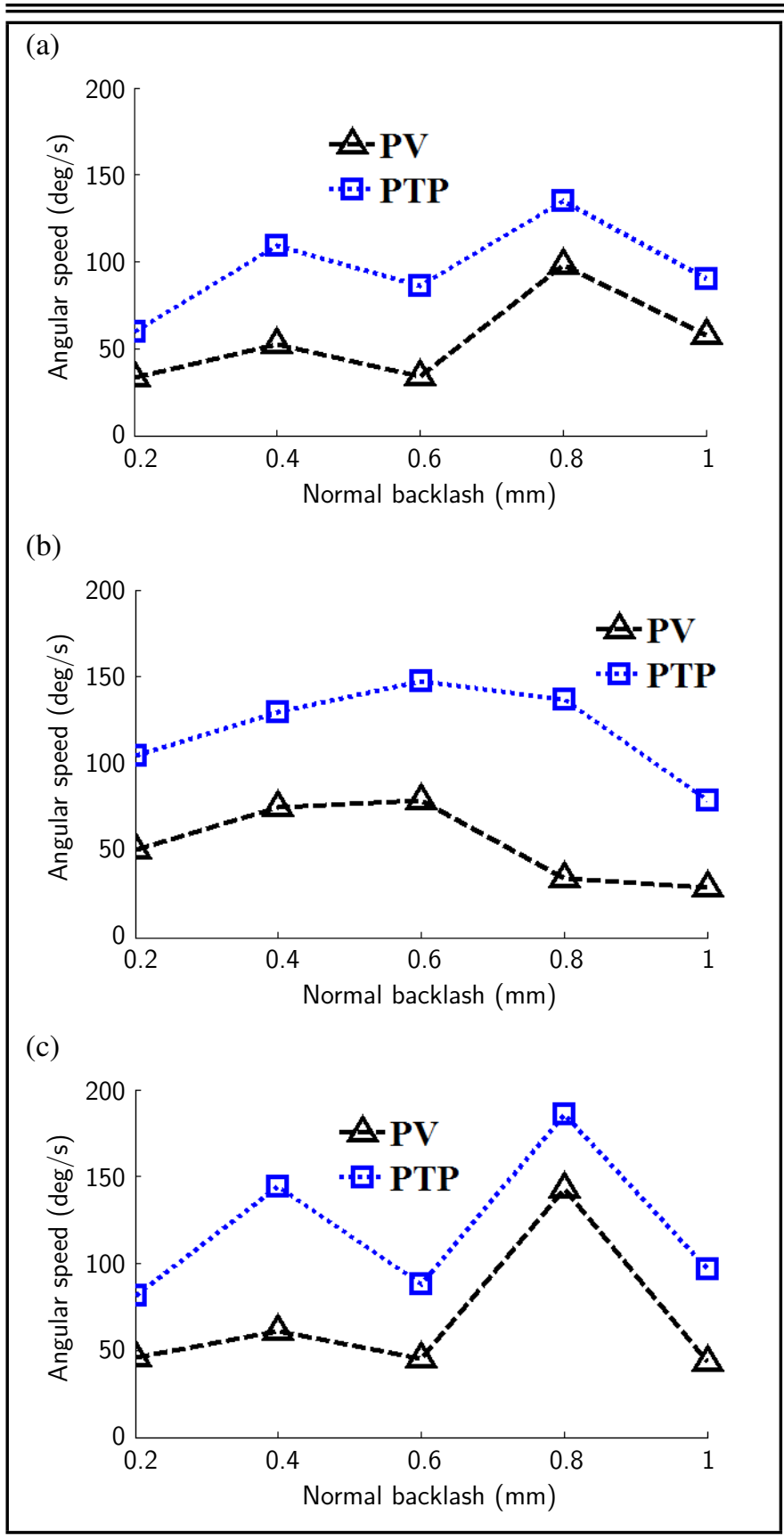

Figure 7. Influence of the backlash on the angular speed of the friction disc with $\eta_{p}=0.0125 \mathrm{~mm}$. (a) $n_{c}=300 \mathrm{r} / \mathrm{min}$, (b) $n_{c}=600 \mathrm{r} / \mathrm{min}$, and (c) $n_{c}=1200 \mathrm{r} / \mathrm{min}$.

radial clearance and backlash can be useful for decreasing the vibrations and impact forces of the friction disc in the planetary transmission system. It also seems the MBD method can be applied to predict the vibrations and impact forces of the planetary transmission system. Some specific conclusions are listed as follows:

(1) When the bearing clearance is from $0.0125 \mathrm{~mm}$ to $0.0225 \mathrm{~mm}$, the minimum vibration displacement, angular speed, and impact force located at the friction disc teeth are observed.

(2) When the backlash between the friction disc and ring gear is $0.2 \mathrm{~mm}$, the minimum vibration displacement and angular speed are observed.

(3) When the backlash between the friction disc and ring gear is larger than $0.2 \mathrm{~mm}$, a smaller bearing clearance can obtain a smaller vibration displacement.

(4) For a low input speed, a larger backlash between the fric-

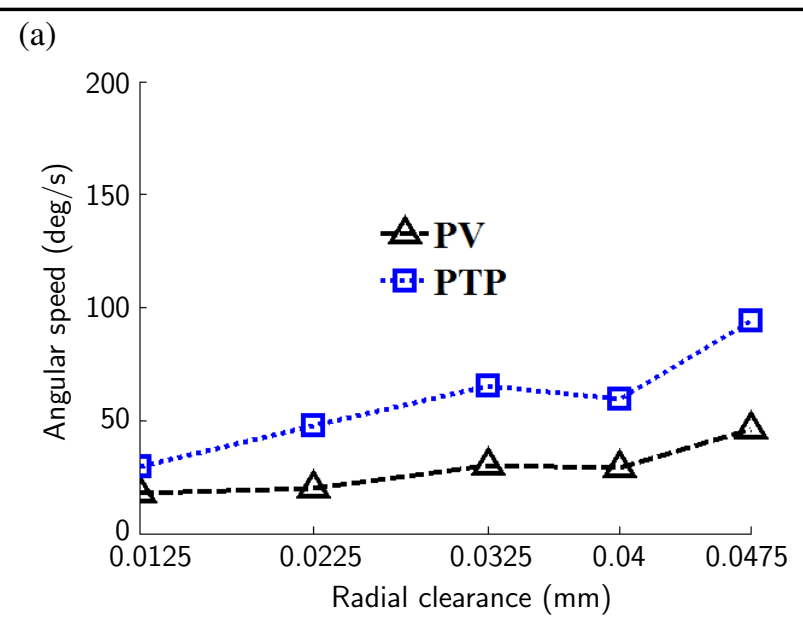

(b)

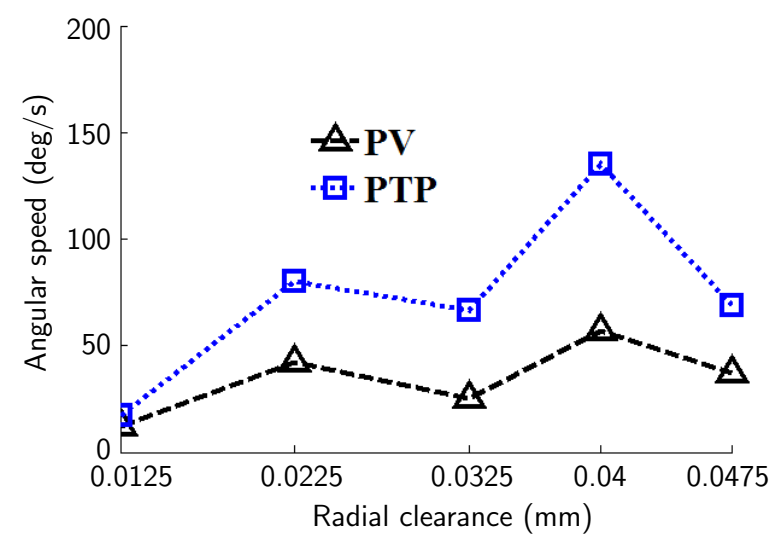

(c)

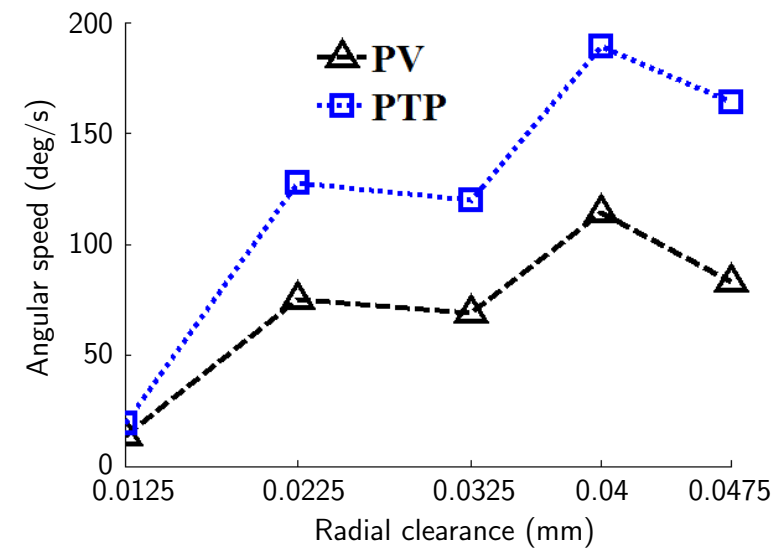

Figure 8. Influence of the backlash on the angular speeds of the friction disc with $n_{c}=1200 \mathrm{r} / \mathrm{min}$. (a) $d_{t}=0.2 \mathrm{~mm}$, (b) $d_{t}=0.3 \mathrm{~mm}$, and (c) $d_{t}=$ $0.4 \mathrm{~mm}$.

tion disc and ring gear can obtain a smaller impact force between the friction disc and ring gear. When the input speed is larger than $1200 \mathrm{r} / \mathrm{min}$, a larger backlash between the friction disc and ring gear will produce a larger impact force.

\section{REFERENCES}

1 Chaari, F., Fakhfakh, T., Haddar M. Dynamic analysis of a planetary gear failure caused by tooth pitting and cracking. Journal of Failure Analysis and Prevention, (2006), 6, 7378. https://dx.doi.org/10.1361/154770206X99343

2 Wang, Y. Tooth damage evaluation method of friction plate 


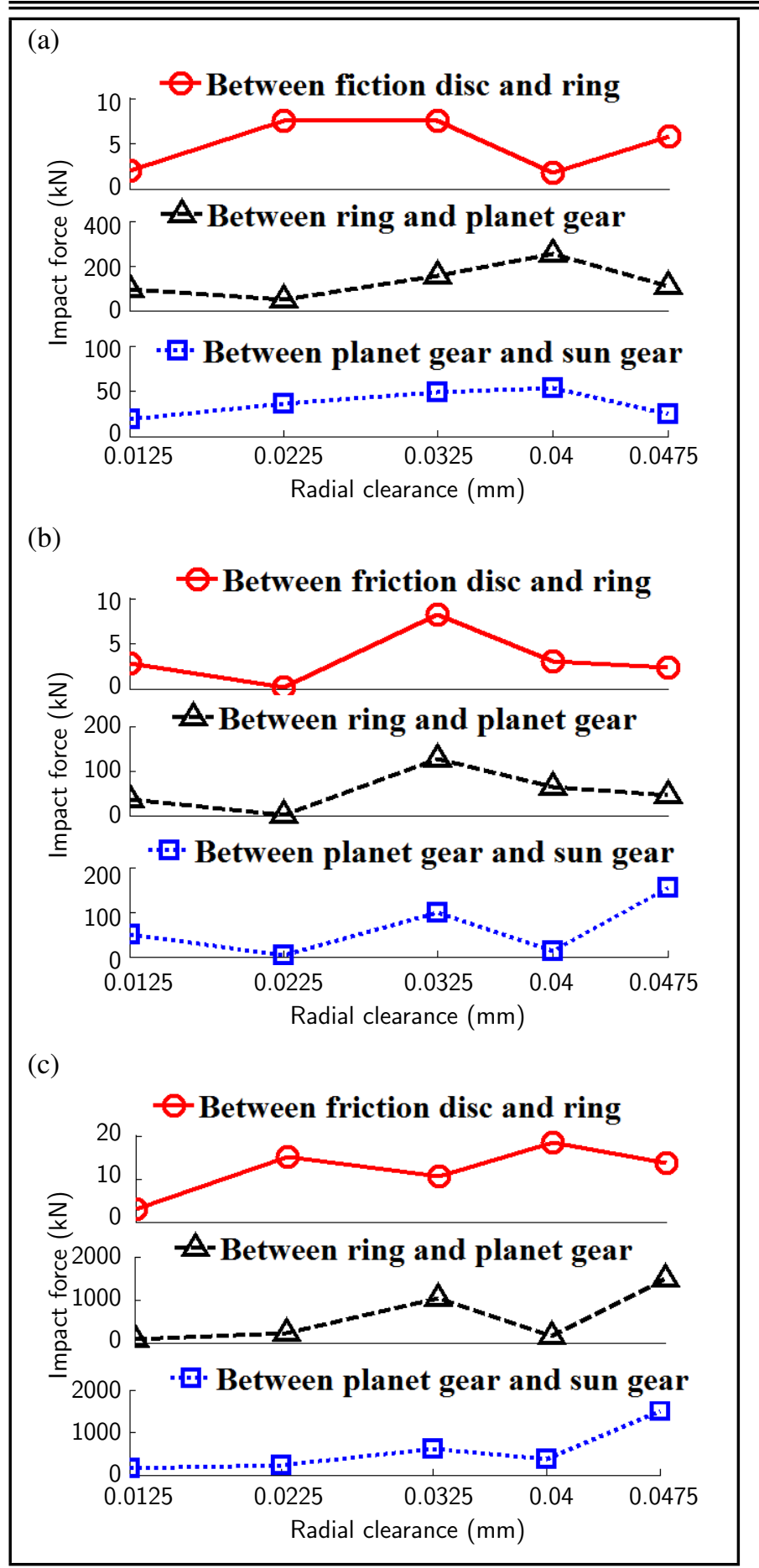

Figure 9. Influence of the radial clearance of the planet bearing on the impact force of the friction disc with $d_{t}=0.01 \mathrm{~mm}$. (a) $n_{c}=300 \mathrm{r} / \mathrm{min}$, (b) $n_{c}=600 \mathrm{r} / \mathrm{min}$, and (c) $n_{c}=1200 \mathrm{r} / \mathrm{min}$.

under impact load. Chongqing University, Master thesis, (2017).

3 Mackin, T. J., Noe, S. C., Ball, K. J. Thermal cracking in disc brakes. Engineering Failure Analysis, (2002), 9(1), 63-76. https://dx.doi.org/10.1016/S1350-6307(00)00037-6

4 Boniardi, M., Errico, F. D., Tagliabue, C., Gotti, G., and Perricone, G. Failure analysis of a motorcycle brake disc. Engineering Failure Analysis, (2006), 13(6), 933-945.

5 Lim, C. H., Goo, B. C. Development of compacted vermicular graphite cast iron for railway brake discs. Metals and Materials International, (2011), 17(2), 199-205. (a)

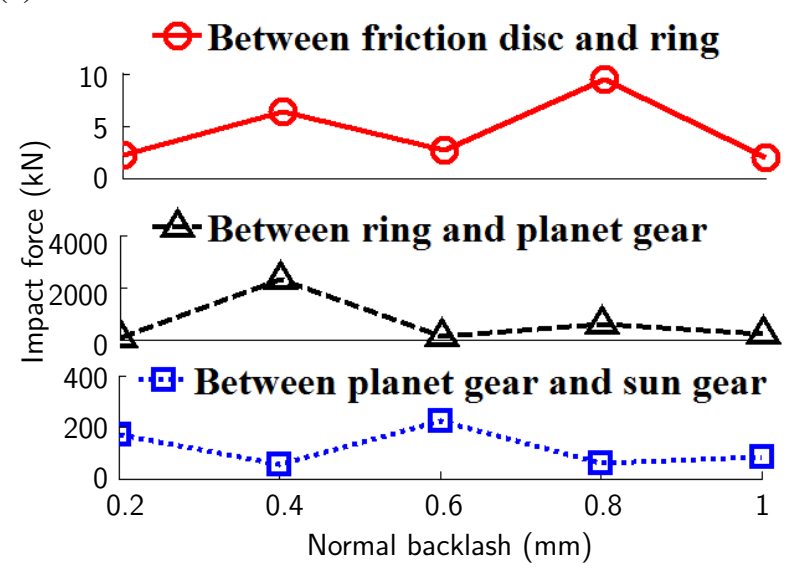

(b)

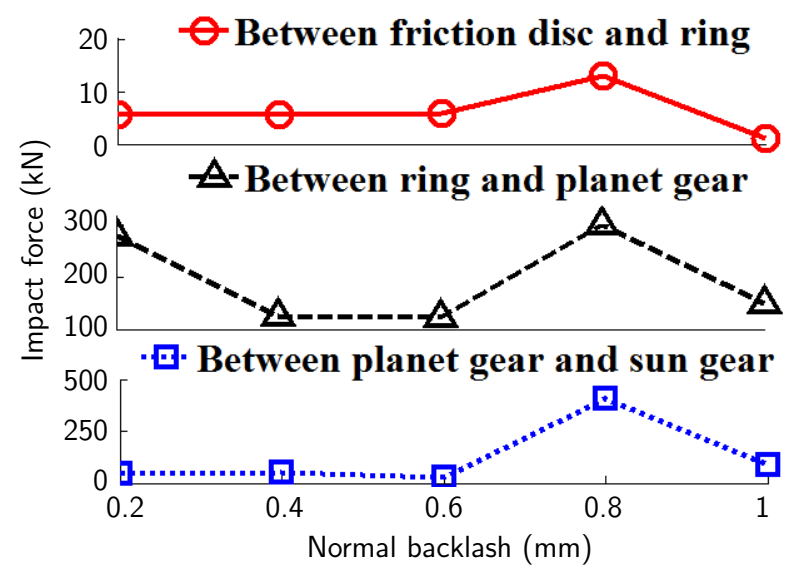

(c)

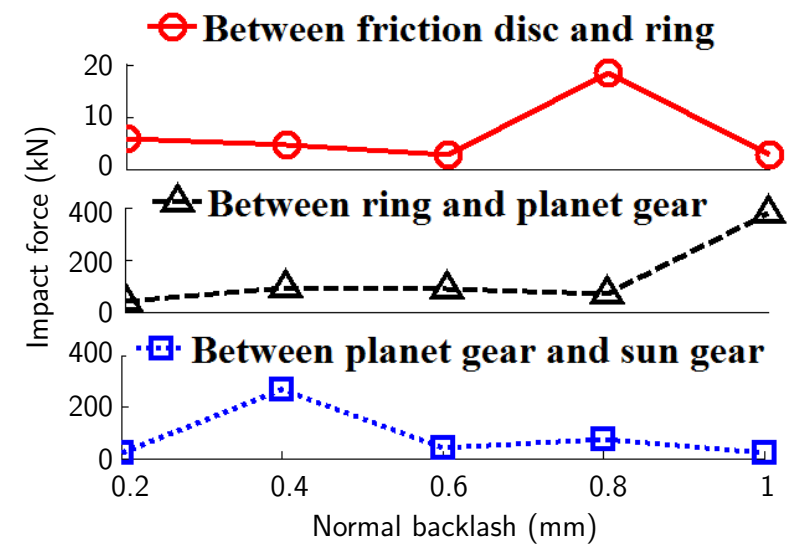

Figure 10. Influence of the backlash on the impact force of the friction disc with $\eta_{p}=0.0125 \mathrm{~mm}$. (a) $n_{c}=300 \mathrm{r} / \mathrm{min}$, (b) $n_{c}=600 \mathrm{r} / \mathrm{min}$, and (c) $n_{c}=1200 \mathrm{r} / \mathrm{min}$.

${ }^{6}$ Goo, B. C., Lim, C. H. Thermal fatigue of cast iron brake disk materials. Journal of mechanical science and technology, (2012), 26(6), 1719-1724. https://dx.doi.org/ $10.1007 / \mathrm{s} 12206-012-0435-2$

7 Majcherczak, D., Dufrénoy P. Dynamic analysis of a disc brake under frictional and thermomechanical internal loading. Archive of Applied Mechanics, (2006), 75(8-9), 497512. https://dx.doi.org/10.1007/s00419-005-0431-4

8 Kang, J., Krousgrill, C. M., Sadeghi, F. Dynamic instability of a thin circular plate with friction interface and its application to disc brake squeal. Jour- 


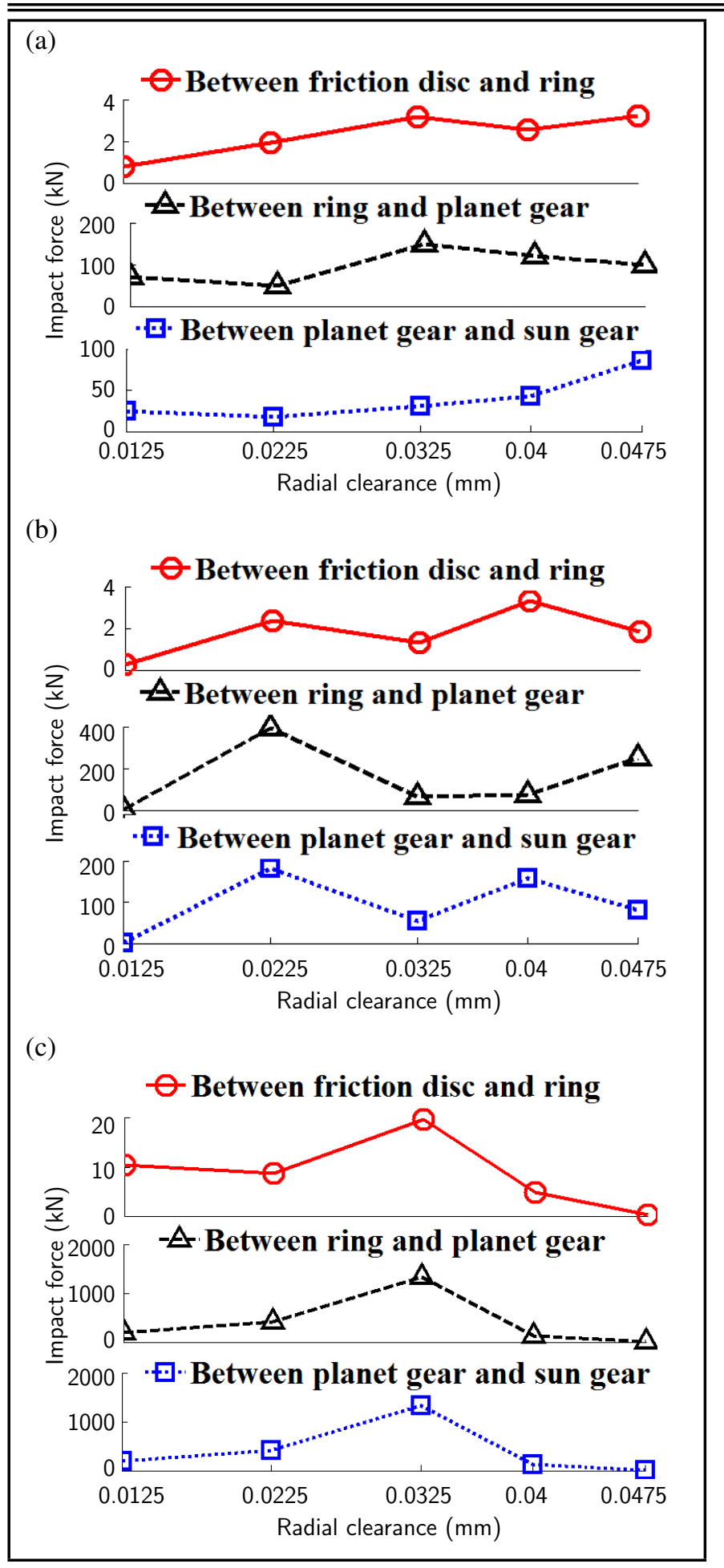

Figure 11. Influence of the backlash on the impact forces of the friction disc with $n_{c}=1200 \mathrm{r} / \mathrm{min}$ (a) $d_{t}=0.2 \mathrm{~mm}$, (a) $d_{t}=0.3 \mathrm{~mm}$, (a) $d_{t}=0.4 \mathrm{~mm}$.

nal of Sound and Vibration, (2008), 316(1), 164-179. https://dx.doi.org/10.1016/j.jsv.2008.02.041

9 Zeng, J., Luo, R. Non-linear analysis of disc brake-induced vibrations for railway vehicles. Journal of Rail and Rapid Transit, (2011), 225(1), 48-56. https://dx.doi.org/10.1243/09544097JRRT307

10 Olshevskiy, A., Olshevskiy, A., Berdnikov, O., Kim, C. Finite element analysis of railway disc brake considering structural, thermal, and wear phenomena. Journal of Mechanical Engineering Science, (2012), 226(7), 1845-1860. https://dx.doi.org/10.1177/0954406211428705
11 Sfarni, S., Bellenger, E., Fortin, J., Malley, M. Numerical and experimental study of automotive riveted clutch discs with contact pressure analysis for the prediction of facing wear. Finite Elements in Analysis and Design, (2011), 47(2), 129-141. https://dx.doi.org/10.1016/j.finel.2010.08.007

12 Li, S. L., Pan, J. L., Yin, H. B. Analysis of vibration characteristics of friction plate based on rigid-flexible coupling model. Key Engineering Materials, (2014), 572, 480-484. https://dx.doi.org/10.4028/www.scientific.net/KEM.572.480

13 Li, S. L., Pan, J. L., Zhao, X. Y. Coupling effect between gear backlash of friction plate and axial separation gap in multi-friction pairs. Key Engineering Materials. (2014), 572, 471-475. https://dx.doi.org/10.4028/www.scientific.net/KEM.572.471

14 Olshevskiy, A., Kim, C. W., Yang, H. I., Olshevskiy, A. Wear simulation for the centre plate arrangement of a freight car. Vehicle System Dynamics, (2015), 53(6), 856876. https://dx.doi.org/10.1080/00423114.2015.1023319

15 Wei, D., Ruan, J., Zhu, W., Kang, Z. Properties of stability, bifurcation, and chaos of the tangential motion disk brake. Journal of Sound and Vibration, (2016), 375, 353365. https://dx.doi.org/10.1016/j.jsv.2016.04.022

16 Kahraman, A., Kharazi, A. A., Umrani, M. A deformable body dynamic analysis of planetary gears with thin rims. Journal of Sound and Vibration, (2003), 262(3), 752-768. https://dx.doi.org/10.1016/S0022-460X(03)00122-6

17 Ambarisha, V. K., Parker, R. G. Nonlinear dynamics of planetary gears using analytical and finite element models. Journal of Sound and Vibration, (2007), 302(3), 577-595. https://dx.doi.org/10.1016/j.jsv.2006.11.028

18 Lethé, G., Cuyper, J. D., Kang, J., Furman, M., Kading, D. Simulating dynamics, durability and noise emission of wind turbines in a single CAE environment. Journal of Mechanical Science and Technology, (2009), 23(4), 10891093. https://dx.doi.org/10.1007/s12206-009-0346-z

19 Helsen, J., Vanhollebeke, F., Marrant, B., Vandepitte, D., Desmet, W. Multibody modelling of varying complexity for modal behaviour analysis of wind turbine gearboxes. Renewable Energy, (2011), 36(11), 3098-3113. https://dx.doi.org/10.1016/j.renene.2011.03.023

20 Xing, Y., Moan, T. Multi-body modelling and analysis of a planet carrier in a wind turbine gearbox. Wind Energy, (2013), 16(7), 1067-1089. https://dx.doi.org/10.1002/we.1540

21 Helsen, J., Marrant, B., Vanhollebeke, F., DeConinck, F., Berckmans, D., Vandepitte, D., and Desmet, W. Assessment of excitation mechanisms and structural flexibility influence in excitation propagation in multimegawatt wind turbine gearboxes: experiments and flexible multibody model optimization. Mechanical Systems and Signal Processing, (2013), 40(1), 114-135. https://dx.doi.org/10.1016/j.ymssp.2012.12.001

22 Jin, X., Li, L., Ju, W., Zhang, Z., Yang, X. Multibody modeling of varying complexity for dynamic analysis of largescale wind turbines. Renewable Energy, (2016), 90, 336351. https://dx.doi.org/10.1016/j.renene.2016.01.003 
${ }^{23}$ Li, Y., Castro, A. M., Martin, J. E., Sinokrot, T., Prescott, W., and Carrica P. M. Coupled computational fluid dynamics/multibody dynamics method for wind turbine aero-servo-elastic simulation including drivetrain dynamics. Renewable Energy, (2017), 101, 1037-1051. https://dx.doi.org/10.1016/j.renene.2016.09.070

${ }^{24}$ Ma, H., Song, R. Z., Pang, X., Wen, B. C. Timevarying mesh stiffness calculation of cracked spur gears. Engineering Failure Analysis, (2014), 44, 179-194. https://dx.doi.org/10.1016/j.engfailanal.2014.05.018

25 Ma, H., Zeng, J., Feng, R. J., Pang, X., Wang, Q. B., Wen, B. C. Review on dynamics of cracked gear systems. Engineering Failure Analysis, (2015), 55, 224-245.

26 Ma, H., Pang, X., Feng, R. J., Song, R. Z., Wen, B. C. Fault features analysis of cracked gear considering the effects of the extended tooth contact. Engineering Failure Analysis, (2015), 48, 105-120. https://dx.doi.org/10.1016/j.engfailanal.2014.11.018

27 Yu, W., Mechefske, C. K., Timusk, M. The dynamic coupling behavior of a cylindrical geared rotor system subjected to gear eccentricities. Mechanism and Machine Theory, (2017), 107, 105-122. https://dx.doi.org/10.1016/j.mechmachtheory.2016.09.017

28 Yu, W., Mechefske, C. K., Timusk, M. Effects of tooth plastic inclination deformation due to spatial cracks on the dynamic features of a gear system. Nonlinear Dynamics, (2017), 87, 2643-2659. https://dx.doi.org/10.1007/s11071016-3218-y

29 Xiang, L., Gao, N., Hu, A. Dynamic analysis of a planetary gear system with multiple nonlinear parameters. Journal of Computational \& Applied Mathematics, (2018), 327, 325340. https://dx.doi.org/10.1016/j.cam.2017.06.021

30 Xin, W. Stability research of multistage gear transmission system with crack fault. Journal of Sound and Vibration, (2018), 434, 63-77. https://dx.doi.org/10.1016/j.jsv.2018.07.037

31 Liang, X., Zuo, M. J., Patel, T. H. Evaluating the time-varying mesh stiffness of a planetary gear set using the potential energy method. Journal of $\mathrm{Me}$ chanical Engineering Science, (2014), 228, 535-547. https://dx.doi.org/10.1177/0954406213486734

32 Xue, S., Wang, C., Howard, I., Lian, P., Chen G. The diagnostic analysis of the fault coupling effects in planet bearing. Engineering Failure Analysis, (2020), 108, 104266. https://dx.doi.org/10.1016/j.engfailanal.2019.104266

33 Liu, J. A dynamic modelling method of a rotorroller bearing-housing system with a localized fault including the additional excitation zone. Journal of Sound and Vibration, (2020), 469, 115-144. https://dx.doi.org/10.1016/j.jsv.2019.115144

34 Lynagh, N., Rahnejat, H., Ebrahimi, M., Aini., R. Bearing induced vibration in precision high speed routing spindles. International Journal of Machine Tools and Manufacture, (2000), 40(4), 561-577.
35 Jiang, H., Liu, F. Dynamic modeling and analysis of spur gears considering friction-vibration interactions. Journal of the Brazilian Society of Mechanical Sciences and Engineering, (2017), 39(12), 4911-4920.

36 Liu, J., Shao, Y. An improved analytical model for a lubricated roller bearing including a localized defect with different edge shapes. Journal of Vibration and Control, (2018), 24(17), 3894-3907. https://dx.doi.org/10.1177/1077546317716315

37 Guo, Y., Parker, R. G. Dynamic modeling and analysis of a spur planetary gear involving tooth wedging and bearing clearance nonlinearity. European Journal of Mechanics A-solids, (2010), 29(6), 1022-1033. https://dx.doi.org/10.1016/j.euromechsol.2010.05.001

38 Guo, Y., Parker, R. G. Dynamic analysis of planetary gears with bearing clearance. Journal of Computational and Nonlinear Dynamics, (2012), 7(4), 41002. https://dx.doi.org/10.1115/1.4005929

39 Raghuwanshi, N. K., Parey, A. Effect of back-side contact on mesh stiffness of spur gear pair by finite element method. Procedia Engineering, (2017), 173, 1538-1543. https://dx.doi.org/10.1016/j.proeng.2016.12.239

40 Moshrefzadeh, A., Fasana, A. Planetary gearbox with localised bearings and gears faults: simulation and time/frequency analysis. Meccanica, (2017), 52(15), 37593779. https://dx.doi.org/10.1007/s11012-017-0680-7

41 Liu, G., Hong, J., Parker, R. G. Influence of simultaneous time-varying bearing and tooth mesh stiffness fluctuations on spur gear pair vibration. Nonlinear Dynamics, (2019), 97(2), 1403-1424. https://dx.doi.org/10.1007/s11071-01905056-9

42 Zhang, X., Tang, X., Yang, W. Analysis of transmission error and load distribution of a hoist two-stage planetary gear system. Journal of Multi-body Dynamics, (2019), 233(1), 3-16. https://dx.doi.org/10.1177/1464419318770886

43 MSC Adams, MSC Adams/View help/Solver help, 2012.

44 Liu, J., Xu, Z., Zhou, L., Yu, W., Shao, Y. A statistical feature investigation of the spalling propagation assessment for a ball bearing. Mechanism and Machine Theory, (2019), 131, 336-350. https://dx.doi.org/10.1016/j.mechmachtheory.2018.10.007

45 Liu, J., Tang, C., Wu, H. An analytical calculation method of the load distribution and stiffness of an angular contact ball bearing. Mechanism and Machine Theory, (2019), 142, 103597. https://dx.doi.org/10.1016/j.mechmachtheory.2019.103597

46 Liu, J., Shao, Y. Dynamic modeling for rigid rotor bearing systems with a localized defect considering additional deformations at the sharp edges. Journal of Sound and Vibration, (2017), 398, 84-102. https://dx.doi.org/10.1016/j.jsv.2017.03.007 